\title{
Intracerebral hemorrhage after external ventricular drain placement: an evaluation of risk factors for post-procedural hemorrhagic complications
}

\author{
A. Shaun Rowe ${ }^{1 *}$, Derrick R. Rinehart ${ }^{2}$, Stephanie Lezatte ${ }^{3}$ and J. Russell Langdon ${ }^{4}$
}

\begin{abstract}
Background: The objective of this study was to evaluate and identify the risk factors for developing a new or enlarged intracranial hemorrhage $(\mathrm{ICH})$ after the placement of an external ventricular drain.

Methods: A single center, nested case-control study of individuals who received an external ventricular drain from June 1, 2011 to June 30, 2014 was conducted at a large academic medical center. A bivariate analysis was conducted to compare those individuals who experienced a post-procedural intracranial hemorrhage to those who did not experience a new bleed. The variables identified as having a $p$-value less than 0.15 in the bivariate analysis were then evaluated using a multivariate logistic regression model.

Results: Twenty-seven of the eighty-one study participants experienced a new or enlarged intracranial hemorrhage after the placement of an external ventricular drain. Of these twenty-seven patients, 6 individuals received an antiplatelet within ninety-six hours of external ventricular drain placement $(p=0.024)$. The multivariate logistic regression model identified antiplatelet use within $96 \mathrm{~h}$ of external ventricular drain insertion as an independent risk factor for post-EVD ICH (OR 13.1; 95\% Cl 1.95-88.6; $p=0.008$ ).

Conclusion: Compared to those study participants who did not receive an antiplatelet within $96 \mathrm{~h}$ of external ventricular drain placement, those participants who did receive an antiplatelet were 13.1 times more likely to exhibit a new or enlarged intracranial hemorrhage.
\end{abstract}

Keywords: Ventriculostomy, Cerebral hemorrhage, Risk factors, Retrospective studies, External ventricular drain, Prevention and control

\section{Background}

External ventricular drains (EVD) are one of the most commonly performed neurosurgical procedures. They are used to provide real time intracranial pressure monitoring and treatment of elevated intracranial pressure [1, 2]. EVDs are often employed during the management of disease states such as traumatic brain injury, spontaneous intracranial hemorrhage (ICH), hydrocephalus, ventriculitis, and meningitis [1]. Though considered relatively safe,

\footnotetext{
* Correspondence: arowe@uthsc.edu

${ }^{1}$ College of Pharmacy, Department of Clinical Pharmacy and Translational Science, The University of Tennessee Health Science Center, 1924 Alcoa Highway, Box 117, Knoxville, TN 37920, USA

Full list of author information is available at the end of the article
}

complications such as hemorrhage, infection, and malposition do occur [2].

The rate of EVD-associated hemorrhage ranges from 18 to $41 \%$, and recent articles have suggested possible risk factors associated with hemorrhage. These risk factors include age, decreased platelets on admission, and increased number of EVD attempts [3-5]. In addition, a recent consensus statement released by the Neurocritical Care Society provides a "good practice statement" suggesting that the reversal of anticoagulants should occur prior to insertion of an EVD except in dire circumstances, and provides a conditional recommendation based on low quality of evidence that patients with an EVD and at high risk of venous thromboembolism 
(VTE) should receive pharmacologic VTE prophylaxis once intracranial hemorrhage is stable or absent [2]. As suggested by the level of this recommendation, literature concerning the effects of perioperative use of antiplatelet and anticoagulant agents in patients with an EVD is limited.

Because of the paucity of data concerning the use of VTE prophylaxis and antiplatelet medications in patients with an EVD, we sought to evaluate these and other potential risk factors for intracerebral hemorrhage following placement of an EVD.

\section{Methods}

This was a nested case-control study designed to evaluate the risk factors associated with new or enlarged intracranial hemorrhage in patients with EVDs. The study was approved by The University of Tennessee Graduate School of Medicine Institutional Review Board committee. All patients included in this study were 18 years of age or older who had an EVD placed between June 1, 2011 and June 30, 2014. Those individuals without a pre-procedural and/or a post-procedural cranial computed tomography $(\mathrm{CT})$ scan were excluded from the study.

Clinical and radiographic data including baseline demographics, EVD indication, coagulation parameters, anticoagulant use, antiplatelet use, Glasgow Coma Score (GCS), and presence of new or enlarged intracranial hemorrhage were collected through a retrospective review of the electronic medical record. If the cranial CT after EVD placement demonstrated a new or enlarged catheter-related bleed, the individual was grouped into a cohort as having evidence of a post-EVD ICH. All head CT scans with any evidence of a new or enlarged bleed were reviewed and quantified by a medical professional. Hemorrhage was specifically defined as a new or enlarged ICH on the ipsilateral side of EVD insertion or catheter tract hemorrhage of greater than $5 \mathrm{ml}$ in volume or greater than $5 \mathrm{~mm}$ in any diameter as seen on CT scan after the placement of the EVD. If the bleed did not meet this predefined threshold, the individual was then removed from the EVD-related bleed cohort and grouped with those who did not experience a hemorrhagic complication.

The primary endpoint of this study was the identification of potential risk factors for new or enlarged intracranial hemorrhage after the placement of an EVD. Secondary endpoints included in-hospital mortality, hospital length of stay, and EVD duration in those with new or enlarged ICH and those without new or enlarged ICH.

Statistical analyses were conducted with SAS (SAS Institute, Cary, NC, Version 9.4 TS1M4). Continuous data were evaluated for normality using Shapiro-Wilk or Kolmogorov-Smirnov tests and visual evaluation of histograms. A bivariate analysis was conducted to compare participants considered to have a new or enlarged ICH after EVD placement to those grouped as having no evidence of new ICH after EVD placement. Normally distributed continuous variables were tested for statistical significance using a Student's T-test and the non-normal continuous variables were compared with a Mann-Whitney U test. Nominal data was compared with a Chi-squared test or Fisher's exact test, as appropriate. To identify the independent risk factors for EVDassociated hemorrhage, the variables with a $p<0.15$, in which all data points were recorded, were evaluated using a multivariate logistic regression model.

\section{Results}

Of the 126 patients evaluated for study inclusion, 81 patients were included. The remaining 45 patients were excluded because of age being less than 18 or the lack of both a pre- and post-procedural head CT scan. Of the 81 patients studied, 27 (33.3\%) had evidence of a new or enlarged ICH after the placement of an EVD. Full baseline demographics and classification of new or enlarged hemorrhages can be seen in Tables 1 and 2 respectively. When the groups were compared, there were no statistically significant differences with respect to age, EVD indication, history of hypertension, presence of preadmission anticoagulant use, or presence of preadmission antiplatelet use.

Among the 27 patients who suffered a post-EVD ICH, only $1(3.7 \%)$ received an anticoagulant and only 1 (3.7\%) received an antiplatelet in the time from admission to time of EVD insertion. Overall, no statistically significant difference was found between patients who experienced a post-EVD ICH and those who did not with regard to preprocedural GCS, International Normalized Ratio (INR), and antithrombotic use (Table 3).

As it relates to our primary outcome of identifying risk factors for new or enlarged $\mathrm{ICH}$ after placement of an EVD, several statistically significant differences were identified in the post-procedural period (Table 4). As it relates to postoperative anticoagulant use, less patients in the post-EVD ICH group received an anticoagulant within $96 \mathrm{~h}$ of EVD insertion (14 [25.9\%] vs. 2 [7.4\%]; $p=0.048)$. Conversely, more patients in the post-EVD $\mathrm{ICH}$ group received an antiplatelet within $96 \mathrm{~h}$ of EVD insertion (6 [22.2\%] vs. 3 [5.6\%]; $p=0.0539)$. The type of antiplatelet agent received after EVD insertion can be seen in Table 5. Additionally, the average GCS on postop day 3 and 4 was significantly lower in the group with post-EVD ICH $(3 \pm 6.8$ and $4 \pm 5.3)$ compared to the group without post-EVD ICH $(8 \pm 10$ and $9 \pm 10)$.

The variables that met the criteria for inclusion in the multivariate logistic regression model were postoperative anticoagulant use within $96 \mathrm{~h}$ of EVD insertion, 
Table 1 Baseline Characteristics of Patients

\begin{tabular}{|c|c|c|c|}
\hline Parameter & $\begin{array}{l}\text { No Evidence of New/Enlarged ICH } \\
(n=54)\end{array}$ & $\begin{array}{l}\text { Evidence of New/Enlarged ICH } \\
(n=27)\end{array}$ & $p$-value \\
\hline Age (years), mean $\pm \mathrm{SD}^{\mathrm{a}}$ & $50.4 \pm 20.1$ & $57.8 \pm 17.7$ & 0.109 \\
\hline Male, $n(\%)^{b}$ & $25(46.3)$ & $14(51.9)$ & 0.637 \\
\hline Caucasian, $n(\%)^{\mathrm{b}}$ & $47(87)$ & $24(88.9)$ & 0.617 \\
\hline Indication for EVD, $n(\%)^{\mathrm{b}}$ & & & 0.261 \\
\hline Head Trauma & $16(29.6)$ & $6(22.2)$ & \\
\hline Non-traumatic ICH & $21(38.9)$ & $18(66.7)$ & \\
\hline Hydrocephalus & $10(18.5)$ & $2(7.4)$ & \\
\hline Meningitis/Nentriculitis & $1(1.9)$ & $0(0)$ & \\
\hline Cerebral Edema & $1(1.9)$ & $0(0)$ & \\
\hline Other & $5(9.3)$ & $1(3.7)$ & \\
\hline History of HTN, $n(\%)^{b}$ & $30(55.6)$ & $18(66.7)$ & 0.337 \\
\hline History of Tobacco, $n(\%)^{\mathrm{b}}$ & $16(29.6)$ & $10(37)$ & 0.501 \\
\hline Known Cocaine use, $n(\%)^{c}$ & $2(3.7 \%)$ & $0(0)$ & 0.5500 \\
\hline Pre-admission Anticoagulation, $n(\%)^{c}$ & $3(5.6)$ & $3(11.1)$ & 0.3949 \\
\hline Pre-admission Antiplatelet Therapy, $n(\%)^{\mathrm{b}}$ & $9(16.7)$ & $8(29.6)$ & 0.177 \\
\hline Intracerebral Hemorrhage present on admission, $n(\%){ }^{b}$ & $45(83.3 \%)$ & $24(88.9 \%)$ & 0.5070 \\
\hline
\end{tabular}

Independent samples t-test

${ }^{\mathrm{b}} \mathrm{Chi}$ Square

'Fisher's Exact

postoperative antiplatelet use within $96 \mathrm{~h}$ of EVD insertion, lowest recorded GCS on postoperative day 3, and lowest recorded GCS on postoperative day 4. The logistics regression model only included those statistically significant variables for which $100 \%$ of the data points were available for collection. Thus, only 72 patients were included in the logistic regression model. In the final multivariate model, only the use of an antiplatelet agent within $96 \mathrm{~h}$ of EVD placement was a risk factor for postEVD ICH (OR 13.1, 95\% CI 1.95-88.6; $p=0.008)$. The full logistic regression model can be seen in Table 6 .

As it relates to our secondary outcomes of mortality, a higher proportion of those patients who experienced a new or enlarged ICH after EVD placement died while in the hospital (16 [29.63\%] vs. 17 [62.96\%]; $p=$ 0.0040). However, having a new or enlarged ICH was not associated with a longer hospital length of stay (18 days \pm 14 days vs. $15 \pm 18 ; p=0.1486$ ). Nor was having a new or enlarged ICH after EVD placement related a longer EVD duration ( $8 \pm 7$ days vs. 7 days \pm 8 days; $p=0.8149$ ).

\section{Discussion}

The insertion of an EVD is a commonly performed neurosurgical procedure that is associated with a recognized risk of $\mathrm{ICH}$. The reported rates of secondary hemorrhage after the placement of an EVD vary significantly with documented rates being as high as $41 \%$ [3]. Because of this significant rate of post-EVD ICH, the present study was designed to investigate the risk factors for post-EVD ICH. In our sample of patients, the prevalence of post-EVD ICH was $33.3 \%$. This rate is consistent with the most recent studies that have evaluated EVD-related hemorrhagic complications.

Although several small studies have evaluated whether certain risk factors are predictive of post-ventriculostomy hemorrhage, the findings are relatively inconsistent throughout the literature [3-8]. In a retrospective study, Foreman et al. identified age greater than 50 years, preplacement antithrombotic use, and an INR greater than 1.4 as being risk factors associated with the development of post-EVD hemorrhage [7]. However, the results of two previous studies failed to identify an elevated INR as high

Table 2 Classification of new hemorrhage after EVD Insertion

\begin{tabular}{ll}
\hline Bleed Classification & $\begin{array}{l}\text { Patients with a new hemorrhage after EVD Insertion, } \\
n(\%)\end{array}$ \\
\hline Enlargement of Preexisting (pre-EVD) ICH by $\geq 5 \mathrm{~mL}$ in volume or $\geq 5 \mathrm{~mm}$ in & $11(40.74 \%)$ \\
largest diameter & $10(37.04 \%)$ \\
New Catheter Tract Hemorrhage $\geq 5 \mathrm{~mL}$ in volume or $\geq 5 \mathrm{~mm}$ in largest diameter & $6(22.22 \%)$ \\
Spontaneous New ICH $\geq 5 \mathrm{~mL}$ in volume or $\geq 5 \mathrm{~mm}$ in largest diameter &
\end{tabular}


Table 3 Preprocedural Analysis

\begin{tabular}{|c|c|c|c|}
\hline Parameter & $\begin{array}{l}\text { No Evidence of New/Enlarged ICH } \\
(n=54)\end{array}$ & $\begin{array}{l}\text { Evidence of New/Enlarged ICH } \\
(n=27)\end{array}$ & $p$-value \\
\hline$\overline{\text { Admission GCS, (Median } \pm \text { IQR) }}{ }^{\text {a }}$ & $10 \pm 8.3$ & $7 \pm 9$ & 0.1964 \\
\hline GCS (highest) $24 \mathrm{~h}$ prior to EVD, (Median $\pm \mathrm{IQR})^{\mathrm{a}}$ & $11.5 \pm 9$ & $8 \pm 7$ & 0.2827 \\
\hline GCS (lowest) $24 \mathrm{~h}$ prior to EVD, (Median \pm IQR) ${ }^{\text {a }}$ & & & 0.3437 \\
\hline INR (highest) from admission to EVD, (Median \pm IQR) $(n=76)^{\text {a }}$ & $1.1 \pm 0.2$ & $1.1 \pm 0.2$ & 0.3437 \\
\hline aPTT (highest) from admission to EVD, (Median \pm IQR) ${ }^{a}$ & $25.9 \pm 4.5$ & $27.3 \pm 5.6$ & 0.017 \\
\hline Preprocedural Anticoagulation, $n(\%)^{\mathrm{b}}$ & $4(7.4)$ & $1(3.7)$ & 0.66 \\
\hline $\begin{array}{l}\text { Preprocedural Antiplatelet, } \\
n(\%)^{b}\end{array}$ & $2(3.7)$ & $1(3.7)$ & 1.0 \\
\hline
\end{tabular}

ann-Whitney U

${ }^{\mathrm{b}} \mathrm{Chi}$ Square

as 1.6 as being a statistically significant predictor of postEVD ICH $[5,6]$. The results of the single-center, retrospective study conducted by Sussman et al. suggest that age greater than 75 years is an independent predictor of catheter-related bleeding events; however, the results did not identify pre-placement antithrombotic use as a significant risk factor [5]. While advanced age was identified as a risk factor in two independent studies, a study by Maniker et al. suggests that age is not predictive of postventriculostomy hemorrhage [8].

In the present study, we assessed the impact of several different variables on the risk of hemorrhage after EVD insertion. While it has been suggested that advanced age, elevated INR, and hypertension may place patients at a higher risk for experiencing an post-EVD ICH, no statistically significant differences were found between the two groups of this study with respect to age, INR, and hypertension [5, 7]. Additionally, no difference was found between the two groups with respect to the number of passes with the ventricular catheter or the skill and experience of the operator. While controlling for potential confounders, the only variable found to be associated with post-EVD ICH was the postoperative use of an antiplatelet within $96 \mathrm{~h}$ of EVD insertion. Compared to those who did not receive an antiplatelet agent within $96 \mathrm{~h}$ after the placement of an EVD, those study participants who did receive postoperative antiplatelet therapy were 13.1 times (95\% CI 1.95-88.6; $p=0.008)$ more likely to exhibit a new or enlarged $\mathrm{ICH}$. This finding suggests that early postoperative use of an antiplatelet within $96 \mathrm{~h}$ of EVD insertion may significantly increase the risk of secondary hemorrhagic complications.

Although previous studies have failed to identify postplacement antiplatelet use as a significant risk factor for EVD-related hemorrhage, this association is intuitive. In a case-control study by Miller et al., decreased platelet levels on admission were associated with post-EVD hemorrhage [4]. Though thrombocytopenia and antiplatelet use are not the same, the Miller et al. study and our study suggest that decreased platelet activity in the perioperative period may be associated with a higher

Table 4 Post-ventriculostomy Analysis

\begin{tabular}{|c|c|c|c|}
\hline Parameter & $\begin{array}{l}\text { No Evidence of New/Enlarged ICH } \\
(n=54)\end{array}$ & $\begin{array}{l}\text { Evidence of New/Enlarged ICH } \\
(n=27)\end{array}$ & $p$-value \\
\hline EVD placed by a trainee or mid-level practitioner, $n(\%)^{a}$ & $19(35.19)$ & $8(29.63 \%)$ & 0.6171 \\
\hline Placement Attempts, (Median \pm IQR) $(n=69)^{\mathrm{b}}$ & $1(0)$ & $1(0)$ & 0.8831 \\
\hline Anticoagulation within 96 h of EVD, $n(\%)^{\text {a }}$ & $14(25.9)$ & $2(7.4)$ & 0.048 \\
\hline Prophylactic anticoagulation, $n(\%)^{\text {a, }} d$ & $11(20.4)$ & $2(7.4)$ & $>0.999$ \\
\hline Antiplatelet within $96 \mathrm{~h}$ of EVD, $n(\%)^{c}$ & $3(5.6)$ & $6(22.2)$ & 0.0539 \\
\hline GCS (lowest) POD 1, (Median \pm IQR) ${ }^{b}$ & $6 \pm 6$ & $6 \pm 6$ & 0.17 \\
\hline GCS (lowest) POD 2, (Median \pm IQR) $(n=80)^{b}$ & $6.5 \pm 7.8$ & $4.5 \pm 6.5$ & 0.0624 \\
\hline GCS (lowest) POD 3, (Median \pm IQR) $(n=76)^{\mathrm{b}}$ & $8 \pm 10$ & $3 \pm 6.8$ & 0.0202 \\
\hline GCS (lowest) POD 4, (Median \pm IQR) $(n=72)^{b}$ & $9 \pm 10$ & $4 \pm 5.3$ & 0.0383 \\
\hline
\end{tabular}


Table 5 Type of post-procedural anticoagulant and antiplatelet administered

\begin{tabular}{llll}
\hline & $\begin{array}{l}\text { No Evidence of New/ } \\
\text { Enlarged ICH }\end{array}$ & $\begin{array}{l}\text { Evidence of New/ } \\
\text { Enlarged ICH }\end{array}$ & $p$-value \\
\hline $\begin{array}{l}\text { Anticoagulant } \\
(n=16)\end{array}$ & $n=14$ & $n=2$ & $>0.999$ \\
$\begin{array}{l}\text { Heparin } \\
\text { Enoxaparin }\end{array}$ & $3(21.43)$ & $2(100 \%)$ & \\
$\begin{array}{l}\text { Antiplatelet } \\
(n=9)\end{array}$ & $n=3$ & $0(0)$ & 0.6873 \\
Aspirin & $2(66.67)$ & $n=6$ & \\
Clopidogrel & $1(33.3)$ & $4(66.67)$ & \\
Prasugrel & $0(0)$ & $1(16.67)$ & \\
\hline
\end{tabular}

proportion of post-EVD hemorrhage. Consequently, it may be reasonable to avoid the routine use of antiplatelet therapy within $96 \mathrm{~h}$ after the placement of an EVD. However, antiplatelet agents should not be withheld due to concerns for hemorrhage when indicated for acute, life-threatening conditions.

Our study is not without limitations. As with all retrospective studies, we are limited by the availability of documented data. We excluded a significant number of patients due to incomplete documentation. However, our final logistic regression model had an appropriate fit based on the Hosmer and Lemeshow Goodness-of-Fit test $(p=0.5545)$. Because we were limited by sample size on the number of variables we could put in the logistic regression model, there may be other variables that contribute to the risk of new or enlarged hemorrhage that we were unable to measure. As this was a single center study, the results reported may not be generalizable to all patients undergoing the placement of an EVD. However, our results are consistent with other studies. This contributes to the generalizability of our results.

\section{Conclusion}

In this study, the use of an antiplatelet within $96 \mathrm{~h}$ after the insertion of an EVD was associated with the

Table 6 Multivariate Logistic Regression Predicting for Hematoma Expansion, $N=72$

\begin{tabular}{lllll}
\hline Variable & $\begin{array}{l}\text { Wald Chi } \\
\text { Square } \\
(\mathrm{df}=1)\end{array}$ & $p$-value & $\begin{array}{l}\text { Odds } \\
\text { Ratio }\end{array}$ & $95 \% \mathrm{Cl}$ \\
\hline GCS (lowest) POD 3 & 0.5907 & 0.925 & 1.022 & $0.65-1.6$ \\
GCS (lowest) POD4 & 0.0088 & 0.442 & 0.837 & $0.53-1.3$ \\
$\begin{array}{l}\text { Postoperative } \\
\text { Anticoagulation }\end{array}$ & 2.7454 & 0.098 & 0.193 & $0.03-1.4$ \\
$\begin{array}{l}\text { Postoperative } \\
\text { Antiplatelet }\end{array}$ & 6.9952 & 0.008 & 13.14 & $1.95-88.6$ \\
\hline
\end{tabular}

Hosmer and Lemeshow Goodness-of-Fit $(p=0.5545)$ development of post-EVD ICH. Based on the results from this study, the use of an antiplatelet within $96 \mathrm{~h}$ of EVD placement may significantly increase the risk of hemorrhagic complications. Therefore, when clinically appropriate, it may be reasonable to avoid antiplatelet use in the early postoperative time up to $96 \mathrm{~h}$ after insertion of an EVD.

\section{Abbreviations}

CT: Computed tomography; EVD: External ventricular drain; GCS: Glasgow Coma Score; ICH: Intracranial hemorrhage; INR: International Normalized Ratio; VTE: Venous thromboembolism

\section{Acknowledgements \\ Not applicable}

Funding

Not applicable

\section{Authors' contributions}

$A R, B D, S L, R L$ contributed significant to the initial design of the study. BD and SL contributed significantly to data collection. AR analyzed and performed the statistical analysis for the study. AR, BD contributed significantly to the initial draft of the manuscript. AR, BD, SL, RL all contributed to the review, interpretation of results, editing, and redrafting of the manuscript. All authors read and approved the final manuscript.

\section{Ethics approval and consent to participate}

This study was approved by the University of Tennessee Graduate School of Medicine IRB and was granted a waiver of consent.

\section{Consent for publication}

Not applicable

The datasets used and/or analyzed during the current study are available from the corresponding author on reasonable request.

\section{Competing interests}

Dr. Rowe is a member of the speaker's bureau for Chiesi and Portula; however, neither company has associations with agents that were of use in the current study. No other authors have potential competing interests.

\section{Publisher's Note}

Springer Nature remains neutral with regard to jurisdictional claims in published maps and institutional affiliations.

\section{Author details}

${ }^{1}$ College of Pharmacy, Department of Clinical Pharmacy and Translational Science, The University of Tennessee Health Science Center, 1924 Alcoa Highway, Box 117, Knoxville, TN 37920, USA. 'Department of Pharmacy, Parkwest Medical Center, Knoxville, TN, USA. ${ }^{3}$ The University of Tennessee Medical Center, University Neurocritical Care, Knoxville, TN, USA. ${ }^{4}$ Department of Anesthesiology, The University of Tennessee Graduate School of Medicine, Knoxville, TN, USA.

Received: 15 November 2017 Accepted: 28 February 2018

Published online: 07 March 2018

\section{References}

1. Rosenbaum BP, Vadera S, Kelly ML, Kshettry VR, Weil RJ. Ventriculostomy: frequency, length of stay and in-hospital mortality in the United States of America, 1988-2010. J Clin Neurosci. 2014;21(4):623-32.

2. Fried HI, Nathan BR, Rowe AS, Zabramski JM, Andaluz N, Bhimraj A, Guanci MM, Seder DB, Singh JM. The insertion and Management of External Ventricular Drains: an evidence-based consensus statement : a statement for healthcare professionals from the Neurocritical care society. Neurocrit Care. 2016;24(1):61-81.

3. Gardner PA, Engh J, Atteberry D, Moossy JJ. Hemorrhage rates after external ventricular drain placement. J Neurosurg. 2009;110(5):1021-5. 
4. Miller C, Tummala RP. Risk factors for hemorrhage associated with external ventricular drain placement and removal. J Neurosurg. 2017;126(1):289-97.

5. Sussman ES, Kellner CP, Nelson E, McDowell MM, Bruce SS, Bruce RA,

Zhuang Z, Connolly ES Jr. Hemorrhagic complications of ventriculostomy: incidence and predictors in patients with intracerebral hemorrhage. J Neurosurg. 2014;120(4):931-6.

6. Bauer DF, McGwin G Jr, Melton SM, George RL, Markert JM. The relationship between INR and development of hemorrhage with placement of ventriculostomy. J Trauma. 2011;70(5):1112-7.

7. Foreman PM, Hendrix P, Griessenauer CJ, Schmalz PG, Harrigan MR. External ventricular drain placement in the intensive care unit versus operating room: evaluation of complications and accuracy. Clin Neurol Neurosurg. 2015;128:94-100

8. Maniker AH, Vaynman AY, Karimi RJ, Sabit AO, Holland B. Hemorrhagic complications of external ventricular drainage. Neurosurgery. 2006;59(4 Suppl 2):ONS419-24. discussion ONS424-415

Submit your next manuscript to BioMed Central and we will help you at every step:

- We accept pre-submission inquiries

- Our selector tool helps you to find the most relevant journal

- We provide round the clock customer support

- Convenient online submission

- Thorough peer review

- Inclusion in PubMed and all major indexing services

- Maximum visibility for your research

Submit your manuscript at www.biomedcentral.com/submit
Biomed Central 